\title{
"It's their way of protecting them": Between care and control in an honor context for youths with intellectual disabilities
}

\author{
Lotta Löfgren-Mårtenson, Pernilla Ouis \\ Malmö University \\ Sweden \\ charlotta.lofgren-martenson@mah.se
}

\begin{abstract}
Today's multicultural society is characterized by contradictory sexual norms that may have consequences for youths with intellectual disabilities' possibilities of choosing a partner and expressing their sexuality. However, the body of knowledge concerning the area of youths with intellectual disabilities is limited. This study aims to examine professionals' views on honor-related experiences among youths with intellectual disabilities. The data consists of nine qualitative interviews with professionals in special schools (personal assistants and teachers). In addition, 11 professionals were included at pre-meetings while designing the study. A thematic analysis was conducted while using sexual script as a theoretical framework. The results are presented in the following themes: (1) The professionals' perceptions of the young people's abilities to deal with honor-related experiences; (2) The professionals' opinions of the existence of honor-related experiences among youth with intellectual disabilities; and (3) Descriptions of the professionals' conduct toward the youths with intellectual disabilities concerning honor-related experiences. The analysis shows an honor script geared towards youths with intellectual disabilities, which can be described as a continuum between care and control connected to cultural sexual norms and to the disability. The families' strive for a so-called normality seem to be an important factor in understanding for example arranged marriages among youths with ID. To meet the needs of these youths, the professionals require tools to navigate between care and control in this complicated arena of contradictory sexual and cultural norms.
\end{abstract}

Keywords: professionals in special schools; youth with intellectual disabilities; sexual norms; honor-related experiences; sexual script theory 


\section{Introduction}

One challenge of today's multicultural society is with the parallel and often contradictory cultural norms concerning sexual openness and restrictiveness. Attitudes toward premarital sexual relationships, homosexuality and pornography differ markedly (Löfgren-Mårtenson and Månsson, 2006). Thus, when these are in opposition to the cultural values of the families of young people with intellectual disability (ID), this can result in the restriction for these young persons to choose a partner and express their sexuality (Schlytter and Linell, 2010). For example, to date, approximately 700 million adult women had been married against their will as children (UN, 2016). In addition, today 125 million women and girls live with the consequences of female circumcision (WHO, 2017). One way of labeling these traditional and patriarchal gender structures is to use the concept 'honor-related' violence and oppression that is characterized as a practice which is conducted collectively (Ouis, 2009; Socialstyrelsen, 2016). In this article, we will use the term 'honor-related experiences' (HRE) to capture the broadness of the subject, as these young people's experiences may be subtle or overt. These experiences may not necessarily be violent, but are nevertheless connected to the family's cultural views on sexuality. The Swedish national strategy for Sexual and Reproductive Health and Right (Socialstyrelsen and Folkhälsomyndigheten, 2014) as well as WHO (2016a; 2016b), emphasize that persons with disabilities should be prioritized when it comes to improving sexual health and developing knowledge in this area. Nevertheless, thus far, young people with intellectual disabilities (ID) are an unseen and forgotten group, as well as absent from a social pedagogical perspective. Dychawy Rosner (2016) argues that there is a need of effective models of practice that prevent social vulnerability and disadvantageous living conditions.

It is well documented that youths with ID belong to an exposed group (McCarthy, 2014; Tilley et al, 2012). They are in need lifelong support; thus, how they are treated in their surroundings (by parents and staff members) plays a major role for their sexual options (Löfgren-Mårtenson, 2004). Today, most people with ID live in an inclusive way in society and are much "like everybody else" as a result of the normalization and integration reforms of the 1970s (Gustavsson, 1996/2001). Nevertheless, many continue to live in a sheltered way due to a sense of responsibility and worries about their surroundings, which include the possibility of an unwanted pregnancy and sexual exposure (Desjardins, 2012; LöfgrenMårtenson, 2004). The topic of sexuality is sensitive and complicated, and young people with 
ID are often seen as especially vulnerable (Kousmanen and Starke, 2015; Löfgren-Mårtenson 2012; McCarthy, 2014). One reason is that some characteristics of the disability include deficient abstract thought as well as lessened verbal and communicative abilities (Granlund and Göransson, 2011) which may limit the understanding of sexual norms, codes, and signals (Löfgren-Mårtenson, 2004; 2012).

In addition, most youths with ID have insufficient knowledge of sexuality, the body, and relationships (Löfgren-Mårtenson, 2005) which is, in part, due to inadequate sex education (Löfgren-Mårtenson, 2012). Moreover, it appears to be difficult for youths with ID to come out as homo-, bi- or transsexual Löfgren-Mårtenson, 2009), and this is due to several factors. The lack of role models and heteronormative social arenas play a role, but mainly, it is because of the attitudes of those in their surroundings who do not want them to further challenge society's norms. Consequently, this group appears invisible and are in great need of a social pedagogical approach. (cf. Dychawy-Rosner 2017)

Scientific knowledge on the area of disability, ethnicity, and sexuality is practically nonexistent despite the acknowledgment of its importance (Fuentes, 2008; McDonaugh, 2004, Raghavan, 2009). In the few studies that exist, the focus is on issues of discrimination and oppression (Fuentes, 2008) primarily connected to the overrepresentation of special education students with an ethnic minority background (Lindsay, Pather and Strand, 2006). Lately, persons with ID who are part of an ethnic minority have been termed as "double oppressed" in analyses where concepts such as marginalization and discrimination are central (Fuentes, 2008; Murray-Nyman, 2005). Where connections to sexuality are concerned, studies regarding various ethnic groups' views on sexuality in persons with ID are scattered. For example, Sankhla and Theodore (2015) found that South Asian participants were found to have significantly more negative attitudes toward the sexual control and sexual rights of people with intellectual disabilities compared to white Westerners. Nevertheless, one Swedish survey carried out by the organization, TRIS (Girls Rights in Society), shows that 29 percent of youths with ID are subjected to honor-related oppression and violence (TRIS, 2012). This is referred to as "triple oppressed", meaning that the combination of disability, gender, and ethnicity makes them even more vulnerable than other young people. However, knowledge of how the professionals working in special schools deal with this phenomenon is still limited. 


\section{Aim and research questions}

This pilot study aims to fill in the gap of the lack of research and contribute with in-depth knowledge on the area of honor-related experiences (HRE) among youths with ID. More specifically, the aim is to explore and describe the perceptions and conduct of professionals working in special schools with youths with ID who are between 18-21 years old. The following research questions guide the process:

- What are the professionals' opinions of the youths with IDs' abilities to perceive and handle various and contradictory sexual norms, and more specifically, HRE?

- How do the professionals view and describe their experiences of the youths' HRE in this target group?

- How do the professionals describe their own conduct while handling HRE among youths with ID in special schools?

\section{Method, research approach, and analysis}

In this study, the qualitative method is used with the aim of reaching in-depth knowledge (Denzin and Lincoln, 2003). This method is viewed as valuable when a research area is underexplored (Svensson and Starrin, 1996). Furthermore, this method has been specifically adapted to be used in a flexible way and can capture complicated aspects of the area (Kvale and Brinkman, 2009). This is relevant for our pilot study which consists of individual interviews as well as a focus group. By using both these methods, the participants can engage in a discussion with each other about the subject of interest and collect findings concerning attitudes and experiences (Wibeck, 2010). We were also able to collect data of the informants' presumptions of the area.

An information and consent letter was sent by school leaders to four special schools in a multicultural city with 300,000 inhabitants who represent 177 different nationalities in Southern Sweden. The informants declared their willingness to participate by sending an email back to the researchers. Depending on the informants' schedules and tasks (e.g., as a personal assistant), they could choose to participate in a focus group or an individual interview. The empirical data consist of five individual interviews with professionals working as personal assistants, teachers, special pedagogues, school counselors, and school nurses (all female) and 1 focus group with four professionals working as personal assistants and teachers in special schools (three female and one male). In total, nine informants between the ages of 
31-63 participated. They had been working with pupils with ID from between three months and 30 years. All, except for one in the focus group, and one of the informants were ethnic Swedes. In addition, two pre-meetings were held with1linformants in total attending; during these pre-meetings, five teachers, five personal assistants, and one school leader in special schools discussed and developed the study design and approach.

The individual interviews and the focus group were conducted in the various special schools where the professionals were employed. We were two researchers, both female, with different professional backgrounds. One is a specialist in the field of sexuality and intellectual disability, and the other in sexuality and migration. The latter conducted one individual interview by herself for practical reasons. A semi-structured interview guide, the same for the individual interviews as for the focus group, was used with a set of pre-designed themes following the research questions. The interviews took between 45 minutes and 1.5 hours (the focus group had the longest interview), and they were all recorded and transcribed verbally. The data was then explored and analyzed by using the software program MAXQDA 12. Categories were created on the basis of the research questions and then transformed into analytical codes using chosen theoretical framework. By using an intersectional analysis, this pilot study intends to create an interplay between factors such as disability, sexuality, and ethnicity, which will deepen the knowledge in the research area of youths with ID, and HRE. Grönvik (2008) describe it as striving for a holistic perspective where the interaction and/or intersection of different dimensions is highlighted.

The project follows the Swedish Codex ethical guidelines concerning information, consent, usage of data, and confidentiality (Vetenskapsrådet and Uppsala University, 2017). To maintain confidentiality, no names, ages, or other identifying information will be given in relation to the quotations of the professionals in the presentation of the result.

\section{Theoretical framework}

This pilot study is based on the classic theory by John Gagnon and William Simon (Gagnon and Simon, 2005) of sexual scripts. Here, sexuality is understood in its historical, cultural, and social context. It is through the interplay with others that the individual learns the when? where? how? with whom? and why? of sexuality. Based on this socialization process, one can think of it as of a kind of "manuscript" whereby each culture creates its own norms and 
values. However, postmodern society is characterized by cultural scripts with parallel and often conflicting norms and behavior patterns (Forsberg, 2007; Löfgren-Mårtenson and Månsson, 2006). These scripts are explicitly expressed in each country’s legislation and regulations (e.g., the Marriage Code, etc.). In addition, these scripts can be placed on collective, interpersonal, and intrapsychic levels (Gagnon and Simon, 2005). Collective cultural scripts affect overall societal values regarding sexuality while external, interpersonal scripts organize relationships between people as per society's basic norms. Conversely, internal, intra-psychic scripts specify how an individual should act and react in certain situations. Previous research shows that a restrictive sexual script is directed toward youths with ID (Löfgren-Mårtenson, 2009; 2013). In short, this script reinforces the heterosexual norms linked to the prevailing cultural script, where it is influenced by the overarching restrictive values of the society regarding sexuality and people with ID [cf. Gagnon and Simon, 2005). The preference for relationships based on love and friendship instead of a sexual relationship, which includes heterosexual intercourse, is significant for this script. One important explanation is that the families and caregivers of the youths feel responsible for the youths' sexuality, which are based on concerns about the "darker" sides of sexuality (e.g., unwanted pregnancy, sexual assault, etc.). Therefore, youths with ID are often overprotected. By using the script theory in an honor-related context, we aim to develop the script theory further while analyzing the interviews with the professionals who work in special schools.

\section{Results}

This article will categorize the results from the interviews with professionals in special schools on the following themes: (1) Perceptions of the young people's abilities to deal with HRE; 2) Opinions of HRE among youths with ID; and (3) Descriptions of the professionals' conduct toward the youths with ID and their families concerning HRE h. The quotations are anonymous and presented by the shortenings to $\mathrm{R}$ (for researcher/s), I:1, 2, 3, 4, 5 (for individual interviews) and F:1, 2, 3, 4 (for focus group informants).

\section{Perceptions of youths with ID and their abilities}

The informants state that HRE exist among pupils in special schools, as well as among other youths. This seem to be especially true in the larger multi-cultural cities in Sweden, where norms and values to a larger extend differ when it comes to attitudes to sexuality, homosexuality and bisexuality, romantic relationships, pre-marital sexual experiences, and 
marriage. Youths with ID are perceived by the informants as more vulnerable than other youths when it comes to understanding and processing these contradictory norms. One female professional with an Arabic background explains:

It's hard for them - for those pupils who are born here in Sweden. They have never lived in their home countries. It will be harder for them to understand cultural differences; they live here in Sweden and are brought up with this culture. It is a completely different life. Here, one does not celebrate in the same manner as one does in their home country, and that is often what is special. The girls here are not treated in the same way as in Iraq or Lebanon or Syria. When they go there, it is difficult for them to understand why there is such a difference if you think [in terms of] honor-related violence. [I:4]

However, it is not solely in handling contradictory sexual norms that youths with ID have difficulties. It is also about understanding and being able to think critically about traditional norms; the youths with ID often internalize stereotyped norms concerning sexuality and gender, which makes it even more complicated when it comes to handling contradictory norms. This is discussed in a focus group with both male and female informants:

\footnotetext{
None of our pupils [with ID] understand the norm - what it is, and how to deal with it. It is clear [to them] that [e.g.,] blue is for boys, and pink is for girls. ... [but] they cannot put themselves outside their own position and consider themselves in a critical way. That's how it is, and that's how it always has been. [F:1]
}

In the same way, the young people's dependent situation due to their disability is generally discussed in the focus groups as well as among the individual informants. The intellectual disability limits their ability to oppose their families will not only when it comes to matters related to sexuality but also in other areas of their lives. "They are seldom aware of any alternatives than the one that their parents offer," states one informant in a focus group. Neither do they revolt or argue with their parents during their teenage or early adulthood, which otherwise is common among young people. The informants conclude that a separationand self-dependency phase is more complicated among youths with ID. This makes them even more vulnerable when it comes to the complicatedness of honor-related experiences. The experiences can be quite subtle. One female individual informant states:

We don't react if a girl sits and talks a lot with a guy. It's natural. But we have had parents who 
forbid their girls to talk to the boys in the class. It does not go so far that it becomes a sexual relationship, but it is still a cultural boundary. [I:1]

There seems to be a gender aspect, as the girls are more dependent on their families and more controlled by their parents and siblings. One individual informant describes this:

The girls are kept strictly [confined by their families], and they are only allowed to go to school at certain times [as per the schedule]. They go home when they are supposed to, and they may only talk to their classmates, no others. [I:5]

The informants state that youths with ID lack education on sexuality, relationships, and on how the body works. It is not only that the special schools lack adequate sex education but also that they only address the specific complicatedness of how different cultures view sex education. Some think the focus should be on family values, while others think that this is a subject that should not even be considered at all. One female informant states that some parents protest against sex education; thus, certain pupils with ID do not want to tell their parents that they have had a lesson on the subject. Another female informant suggested that sex education should be part of all subjects, and that the different professionals could have a shared responsibility for teaching and discussing the area:

It is not supposed to be a specific subject [anymore], which I think is a shame. Because then one had to do something, and now everyone hesitates and thinks [teaching sex education] is awkward. [I:3]

In addition to for general information, the girls sometimes need specific counseling connected to honor-related experience, both with it comes to how the material is designed and its content. It should be easy to read - perhaps with no text in certain parts, only pictures suggests one informant. However, it is also important to offer information on sexual rights and health. One female informant who works as a nurse brings up the subject of girls who have been circumcised:

There is much ignorance. A girl here at the special school is pregnant, and she asked me how the baby will come out. And then we have the circumcised girls, who we also try to support. We had a girl from Somalia who had severe period pains and urinary tract infections. She was all tied together and was due to have surgery to be opened up, but then she moved to $\mathrm{X}$ 
[another city]. [I:3]

The informants state that, in general, all youths with ID are vulnerable in a way that is unrelated to gender. They are all in the same dependent situation, and they all have different levels of limited intellectual disability. In addition, as per one informant, questions about sex education should not only be addressed in a group but also during individual counseling sessions [I:1]. However, others point out that girls with ID are much more vulnerable than the boys, and therefore, require more sex education. In line with this, one female informant explains:

I think that girls are more vulnerable to [norms concerning] the body and makeup and appearance. There are several [in their surroundings] who have opinions about this - how to dress or wear makeup, or what boys they are supposed to get together with. [I:2]

From the interviews, it seems to be more common in special schools to divide the students into so-called girl groups than boy groups. The aim of these groups is to conduct sex education while creating opportunities to talk about relationships, body knowledge, and sexuality. Foremost, the girls are invited to these groups and have the professionals' focus. One explanation is that the professionals view the girls as more vulnerable, and the girl groups act as a means to have some understanding of their knowledge and experience. However, some of the professionals are against this kind of polarized gender grouping. Younger colleagues seem to be more opposed to this kind of division of youths with ID. They believe that inclusion in these groups should be based on equality, sexual rights, and gender. This is also a way of including transgender persons and those with different sexual orientations.

\section{Perceptions of honor-related experiences among youths with ID}

The informants also agree about the existence of honor-related experiences among youths with ID, just as they occur among other young people in the same context. The professionals mainly express honor-related experiences as connected to the limited possibilities of choosing a spouse oneself. Further, they describe that the families arrange marriages between their children/young adults with ID and a person from their home country, or if they are Swedish, they chose a person who belongs to the same set of cultural and sexual norms. However, the informants appear to be unsure about what really happens. The pupils with ID often disappear 
during summer vacation and then do not come back to school in the fall. One female individual informant describes this:

Well, when someone is married off ... it's hard for us to tell. We can only speculate. We suspect that right now there is a Swedish girl who is a pupil at the special school who has been married off. She was here for seven years, and she never wanted to quit [school]. [I:1]

The informants describe both young males and females who will have their marriages arranged by their parents. One female informant describes a male pupil with an autistic disorder; he does not talk much about his life, except when it comes to marriage. The following informant gives an example of when the professionals ask him about the future:

"I'm going to marry a girl from Afghanistan," he says. "Have you met this girl?" "No, but my dad has met her." "What is her name?" "I don't know," he says, "But my dad knows." Then another friend said to him, "You must marry her." I think that his father has traveled to Afghanistan to meet this girl, and that her parents have paid for the trip. They're buying gold and clothes, and he must wait until she gets permission to come here, but the boy has not met her. [I:4]

The informants in the focus group discuss some potential reasons for why the families arrange marriages. One could be that, in some cultures, it is perceived as shameful to have a child with disability. Therefore, they may want to hide or diminish the disability through marriage. This may especially be the case in cultures where women are not supposed to go outside or are tied to household tasks - a realistic way of hiding females with ID. This is also a way of normalizing young persons with a disability in cultures where heterosexual marriages are the norm. It becomes a way to make the life of the young person with ID like "everybody else's". One male informant describes this:

I think it's a little bit like, [for example] when there are other relatives in Malmö, and they can say, "My son is getting married," like everyone else can or that "My daughter is marrying," like everyone else's daughters. There is nothing strange about my child - it is about status. [F:4]

Another reason is that a marriage can be a way of arranging protection and care for the young person with IT. Their families might not have the resources to take proper care of the youth, 
or they may worry about the future and what will happen when they cannot take care about them anymore. Then older relatives with a stable income are seen as a good solution. Furthermore, marriage could be an alternative to moving to a group home with staff members who may frequently change. The informants in the focus groups continue to discuss the issue:

They may think that they are leaving them to someone in safe hands - [someone] who will take care of them. It is their way of protecting them instead of moving them to a group home, as we think, we here at the special school think. They may not think that it is the best solution to put their children into strangers' hands - professionals who will be replaced all the time. [F:6]

Another example of honor-related experiences among youths with ID is sexual conduct that challenges the heteronormative norm. Nevertheless, in general, youths with ID who live as homosexuals or bisexuals or who have a transgender identity appear to be uncommon. One informant states that several reasons account for this: Some are quite immature and do not really know if they are heterosexual or homosexual. Moreover, it can be more difficult to "come out" as a homosexual or bisexual person when one is in a dependent situation. The informants in the focus group also state that, in general, much prejudice can be observed among the pupils against homosexual and bisexual persons. However, the reason could be that many of the pupils lack knowledge. One individual informant states,

They don't really understand what it means. I do think that they understand the meaning [in a certain sense], as they can say to a friend, "fucking faggot". We have two guys who are like a married couple, but they are not gay. They are close all the time, and we have fun with them, but they are not very good for each other in a classroom context. They are too close to each other and are not able to concentrate ... [although] we can have fun and ask, "Where is your wife?" They're not homophobic in that way, but in reality, maybe they would [prefer to] be that? I don't know. [I:2]

Nevertheless, some pupils in special schools are open with their sexual orientation, which challenges the heterosexual norm: The informant continues by describing one male pupil with ID's experience:

He can be open about his sexual orientation, but otherwise, it is not very common among our pupils. They are still quite often insecure and searching for their identities. I think they mature later than others. It takes time before you know who you are ... There are so many aspects, and 
it is perhaps more difficult for them. Especially for our Muslim youth, where it is particularly stated that [so-called] sexual deviation is wrong and ugly. [I:1]

Again, despite the lack of knowledge and its general invisibility in society, ethnicity is an additional factor (on top of disability and sexuality) for why it can be more difficult for youths with ID to identify as non-heteronormative. The informants describe different norms in various cultures when it comes to attitudes to LGBTQ persons. Therefore, the attitudes differ among both the pupils and their families. In some cultures, there seems to be a more tolerant attitude to homosexuality and bisexuality. One female informant describes two boys from a country where it is common for same sex persons to hold each other's hands. The informants in the focus group, on the other hand, refer to a family who abandoned their son with ID and threatened him when he came out as homosexual:

There was one male youth living in a shelter house who had no contact with his family because he was gay. His family had completely severed ties with him. [F:6]

\section{Conduct and behavior by the professionals}

The informants in the focus groups as well as in the individual interviews all express that they need more knowledge about how to deal youths with ID who live with honor-related experiences. As it is an unilluminated social phenomenon, the informants point out the importance of developing knowledge and attention to the area. Some of the school nurses and counselors receive supervision about this, but the teachers and the personal assistants do not, despite these latter groups often being in the closest contact with the youths with ID.

The informants describe the lack of guidelines and strategies on honor-related experience. Therefore, when something happens to their pupils with ID which is honor related, they do not know what do to. They seldom discuss this subject in advance, and their reactions are described as "putting out fires". One individual informant states,

There's a lot of "putting out fires", and very little has been discussed in advance. Some employees attend courses because they are particularly interested. One might discuss it when we have a certain project, but we have no [overall] strategy. [I:1]

However, the informant with a different ethnic background than the traditional Swedish 
professionals stated that she is viewed as a source of knowledge for her colleagues. She knows it is easier to understand the parents and families' values and behavior from an insider perspective. The informant further states,

Because I am from the same culture, colleagues ask me, "Can you explain this to us? Why do girls behave like this? Why do they say this or that?" Then I usually explain that it [HRE] is a cultural issue, and the families care about cultural issues. Usually, culture is very important for these families. It means so much to them. [I:4]

As well as helping colleagues, this informant is also a source of knowledge and a role model for the youths with ID that have a cultural background other than ethic Swedish. She continues,

Sometimes they will ask about religion or culture, and I will give an answer even if I do not have that much knowledge. I know a little bit more [than the others] because I have studied religion as a subject. Many of the parents may not have any education. There is nothing wrong with them, but they lack training. Then it can be difficult for the parents because they have no answers, and most young people are curious. They often ask, “why?” [I:4]

In-depth knowledge is also important for other reasons. One informant stated that the professionals sometimes could be moralistic and quick to judge. Opportunities for the professional to reflect about their attitudes could be essential for handling these issues in a more professional manner. It is not always the professionals' own set of cultural norms that are the "right" ones. She explains,

Sometimes I feel that the staff "goes off" too much - that they don't really talk and listen to what the pupil is saying. Some pupils say, "It's okay for me. I want to marry," but then the staff may say, "No, you cannot do so!". You cannot be forced to get married!" They should slow down a bit [about judging] what is right and wrong. But if you are happy with this and agree, it's not a problem. [I:5]

The informants say that it is difficult to know what the right thing to do is, and how to act and treat the young males and females with ID who are exposed to honor-related experiences. They do not want to put the youths in an even more oppressed or more vulnerable situation, by forcing them to choose between what the professionals believe is best as opposed to what 
the parents believe is best. Nevertheless, some informants tell of specific ways of giving the young people more space and opportunities to see their friends or even partners which otherwise would have be impossible. Some have boyfriends or girlfriends, but it is not possible for them to meet outside school hours. One informant states that they have made socalled shadow schedules to create free time in school before the pupils must go home to their families. She explains,

\begin{abstract}
We made a fake schedule, which meant that she was always able to stay at school until $4 \mathrm{pm}$. That's the schedule she shows at home so that she can get some "air" and a little privacy here at school. Maybe then, she can go to the mall with a friend and feel like a normal girl. This has made a big difference for her. [I: 3]
\end{abstract}

The informant continues and describes other ways of supporting the youths with ID. At her school, they also help them with appointments at a youth center or a gynecologist if they need medical care or information about contraception.

I leave the responsibility to the youth clinic. Sometimes, I call the women's clinic - an anonymous request. We had a gynecologist who helped the girls who were circumcised and who faked that they were virgins. I called at one point and counseled her. They [the girls] are often very afraid that their parents will find out. [I: 3]

An additional way of supporting the youths is to strengthen their rights as independent and free humans. An informant with a cultural background from another country describes her conduct:

\footnotetext{
There are girls who take off their head scarf at school, and I always say that there is nothing that stipulates whether they have to wear a head scarf or not. There is no such thing as haram (forbidden) as far as 'hijab' are concerned, [and I say that] "I can tell that to your parents." Then they say, "No, don't tell anyone." [I:4]
}

The informants all state that is important to stress that all pupils, despite their different cultural backgrounds, should attend all lessons and that they all are compulsory. It makes no difference if it is sex education or swimming lessons. However, sometimes parents do not allow their daughters to swim with the boys. One solution is that the professionals will make certain arrangements where the girls have swimming lessons apart from the boys. One 
informant states,

We have this personal assistant [...], she tries to arrange it [the swimming lessons] so that there are only girls when they are swimming. It is important to be able to swim [...]. We must solve it with only girls during these occasions. [I: 5]

The informants in the focus groups and in the individual interviews all agree on the importance of support by their employer. A principal who is aware of the phenomena of honor-related experiences and who acknowledges the importance of further training and competence is essential.

We are a rather new group here in this city. We left about a year ago with my "gang" [of colleagues]. Some of us completed further training in Uppsala [another Swedish city], and now we have had a meeting with our school principal. She is keen [to help] the pupils at our special schools and wants us to learn the signs [of honor-related experiences], and how we can support them. [I:3]

However, in everyday life at their schools, colleagues offer the greatest support. The individual informants all agree about the importance of being able to talk with each other about matters that concern their pupils with ID. This is true even in the focus group:

Yes, that is what we do all the time, no matter if you have the main responsibility for that specific pupil or not. It is our shared responsibility. I would not feel that I stand alone if something like this should happen, [for example], when I talk with authorities or parents. [F:4]

\section{Between care and control - Discussion of a sexual honor script}

To sum up, the results show that the professionals at special schools perceive honor-related experiences as an existing phenomenon among youths with ID, as well as among other youth groups in today's multicultural society. However, they view youths with ID as an especially vulnerable group compared to other youths. Their disability makes it more difficult to understand and review sexual and cultural norms that influence their own options to choose partners and to express sexuality on their own terms. In addition, their dependent situation makes it even more difficult to revolt against strict social and sexual norms. This is especially true concerning sexual conduct that includes premarital sexual relationships as well as those, which challenge the heterosexual norm. Although the professionals perceive young females 
with ID as being more controlled by their families than the young males with ID, the latter also appear to have experiences of, for example, arranged marriages. The professionals interpret one important reason for the existence of honor-related experiences among youths with ID as the family's wish to prepare for the future for the child with a disability both economically and socially. Likewise, arranged marriages seems to be a way of constructing so-called normality by creating a life that is consistent with an "ideal" way of living within a heterosexual marriage and a family of their own. The informants understand this as being both for the young people's own sake as well as the family's. The professionals state that their role in special schools is to inform and explain to the young females and males with ID the consequences of marriage (e.g., intercourse, pregnancy) as well as strengthen their human and sexual rights to choose a partner and sexual lifestyle independently. However, the informants also state the importance of understanding and respecting different cultures and their sexual norms. Ignorance and prejudice can cause tension between families with another cultural background than traditional Swedish and the professionals at the Swedish school. Subsequently, this tension puts the youths with ID in the middle of a complicated tug of war between contradictory norms, while at the same time, they are dependent upon both their relatives and the professionals at the special school. The informants express their own need for knowledge, supervision, and guidelines within in an honor context connected to intellectual disabilities. However, some of them describe receiving existing support from their colleagues as well as from their employers.

This pilot study shows that understanding the strive for so-called normality is one important factor in the multifaceted area of honor-related experiences among youths with ID. Arranging marriages for the young women and men with ID appears to be part of some families' desire to normalize their child with a disability. It is important to note that to have a child with a disability is perceived as shameful in many cultures (Östman, 2008). Therefore, arranged marriages are viewed as an opportunity for the child to have an ordinary life with a spouse and children instead of living in hiding. However, the construction of so-called normality goes two ways: Many youths with ID also want to be like "everybody else" (Löfgren-Mårtenson, 2012) where having a partner and experiencing love and sexuality is seen as an important part of life. Another study is investigating how women with ID construct their identity based on notions of femininity (Barron, 2002). Being a woman is then connected to the traditional norms of finding boyfriends and having children. On a structural level, research shows that 
the normalization principle, which aims for the living conditions for people with disability to be like those of everyone else, also has an inherent stereotypical concept of gender (Angrosino and Zagnoli, 1992; Atkinson and Walmsley, 1995). One reason is that society may not want persons with ID to deviate even further from the norm (Abbott and Howarth, 2007; Peuravaara, 2015). Therefore, homosexuality and bisexuality, for example, appear to be invisible in the group of people with ID (Löfgren-Mårtenson, 2009).

As mentioned, previous research has shown a restrictive sexual script with limitations on sexual conduct for youths with ID (Löfgren-Mårtenson, 2013). Adding factors such as ethnicity and gender to the already restrictive sexual script theory uncovers an "honor script" geared toward a group of youths with ID who live with their families and who are from another cultural background than traditional Swedish. This honor script gives directives on how to have sex, with whom, when, and so on that, in some areas, differs and is stricter than the sexual scripts of liberal western society. Nevertheless, the honor script still might be difficult to understand and to conceptualize for youths with ID while it is tightly connected to the collectives' cultural norms and codes. Therefore, the honor script makes the continuum between care and control even more complicated; it explains both the professionals' and the families' protective actions as well as the avoidance of any non-preferable sexual conduct. From a social pedagogy perspective it is urgent to develop models of empowerment in order to strengthen the young people and to prevent honor related violence (cf. Dychawy Rosner 2017).

\section{Conclusion}

The results show that an honor script is geared toward youths with ID as well as to other youths in families from cultures that differ from those of western society. To meet the needs of these young people, the professionals in special schools need tools to navigate between care and control in this complicated tug of war between different and contradictory sexual and cultural norms.

\section{Limitations}

Further research is required due to the limited data of this pilot study. Nevertheless, the collected qualitative data was thorough and aims to give initial insight into this field of research. It is advised that additional research should address the direct perceptions and 
experiences of youths with ID, which is lacking in the current body of research. In addition, future research questions should address the families' perspectives in a profound way in order to contribute to a holistic perspective on the research area. Finally, including youths with ID in the same research context as other young people and taking into consideration additional factors, such as for example social class, would enhance supplementary knowledge when dealing with the complicatedness of these multicultural challenges.

\section{References}

Abbott, D. and Howarth, J. 2007. Still off-limits? Staff views on supporting gay, lesbian and bisexual people with intellectual disabilities to develop sexual and intimate relationships. Journal of Applied Research in Intellectual Disability 20: 116-126.

Angrosino, M.V. and Zagnoli, L.J. 1992. Gender constructs and social identity; Implications for community-based care of retarded adults. In: Whitehead, T. and Reid, B. (eds.) Gender constructs and social issues. Urbana: University of Illinois Press.

Atkinson, D. and Walmsley, J. A. 1995. Women's place: Issues of gender. In: Philpot, T. and Ward, L. (eds.) Values and Visions: Changing Ideas in Services for People with Learning Difficulties. Oxford: Butterworth-Heinemann.

Barron, K. 2002. Who am I? Women with learning difficulties (re)constructing their selfidentity. Scandinavian Journal of Disability Research 4(1): 58-79.

Denzin, N. K. and Lincoln, Y. S. (eds.) 2003. The landscape of qualitative research: theories and issues. Thousand Oaks: Sage.

Desjardins, M. 2012. The Sexualized Body of the Child: Parents and the Politics of "Voluntary" Sterilization of People Labeled Intellectually Disabled. In: McRuer, R., Mollow, A. (eds.) Sex and Disability. Durham and London: Duke University Press.

Dychawy Rosner, I. 2017. Preventive Intervention in Socio-Pedagogical Social work. Papers on Social Pedagogy 01(6): 24-35.

Forsberg, M. 2007. Brunetter och blondiner: Sex, Relationer och tjejer i det mångkulturella Sverige. [Brunettes and Blondes: Sex, Relations and Chicks in Multi-cultural Sweden]. Lund: Studentlitteratur.

Fuentes, J. 2008. Etnicitet och funktionshinder [Ethnicity and Disability]. In: Grönvik, L., Söder, M. (eds.). Bara funktionshindrad? Funktionshinder och intersektionalitet [Only disabled? Disability and Intersectionality]. Malmö: Gleerups.

Gagnon, J. and Simon, W. 2005. Sexual conduct. The social sources of human sexuality. 2nd 
ed. Chicago: Aldine Publisher Company.

Granlund, M. and Göransson, K. 2011. Utvecklingsstörning [Intellectual Disability]. In: Söderman, L. and Antonson, S. (eds.) Nya Omsorgsboken [The New Book of Social Care] Malmö: Liber.

Grönvik. L. 2008. Sexualitet och funktionshinder [Sexuality and Disability]. In: Grönvik, L Söder, M. (eds.). Bara funktionshindrad? Funktionshinder och intersektionalitet [Disabled only? Disability and Intersectionality]. Malmö: Gleerups.

Gustavsson, A. 1996/2001. Integrering som motkultur - erfarenheter från den första integreringsgenerationen [Integration as a counterculture - experiences from the first generation of integration]. In: Rabe, T. \& Hill, A. (eds.). Boken om integrering. Idé, teori, praktik [A Reader on integration. Idea, theory and practice]. Trelleborg: Studentlitteratur.

Kousmanen, J. and Starke, M. 2015. Access to Sweden s Legal System of Crime Victims with Intellectual Disability Involved in Prostitution Activities. Journal of Policy and Practice in Intellectual Disabilities: 4(2), 255-265.

Kvale, S. and Brinkman, S. 2009. Den kvalitativa forskningsintervjun [The Qualitative Research Interview]. Lund: Studentlitteratur.

Lindsay, G. Pather, S. and Strand, S. 2006. Special Educational Needs and Ethnicity: Issues of Over- and -Under-Representation. Centre for Educational Development, Appraisal and Research. UK, Institute of Education, University of Warwick.

Löfgren-Mårtenson, L. 2004. "May I?” About Sexuality and Love in the New Generation with intellectual disabilities. Sexuality and Disability 22(3): 197-207.

Löfgren-Mårtenson, L. 2009. The Invisibility of Young Homosexual Women and Men with Intellectual Disabilities. Sexuality and Disability 27(1): 21-26.

Löfgren-Mårtenson, L. 2012. "I want to do it right!” A Pilot Study of Swedish Sex Education and Young people with Intellectual Disability. Sexuality and Disability 30(2): 209-225.

Löfgren-Mårtenson, L. 2013. Sexualitet [Sexuality]. BeGreppbart. Malmö: Liber.

Löfgren-Mårtenson, L. and Månsson, S.-A. 2006. “Sex överallt, typ?!” Om unga, kön och pornografi [“Sex everywhere?!” Youth, Gender and Pornography]. Malmö: Gothia.

McCarthy, M. 2014. Women with intellectual disability: Their sexual lives in the 21st century. Journal of Intellectual and Developmental Disability 39(2): 124-131.

McDonagh, P. 2004. Class, ethnicity and intellectual disability: Challenges to writing the story of intellectual disability. Journal of Intellectual Disability Research 6(48): 483.

Murray-Nyman, M. (red.) 2005. Dubbel utsatthet [Double Oppressed]. Sveriges Kristna Råd, 
Stockholm.

Ouis, P. 2009. Honorable traditions? Honour violence, early marriages and sexual abuse against teenage girls in Lebanon, the occupied Palestian Territories and Yemen. International Journal of Children's' Right 17: 445-474.

Peuravaara, K. 2015. "Som en vanlig tjej": Föreställningar om kropp, funktionalitet och femininitet ["Like an Ordinary Girl" Conceptions on body, functionality and feminitity]. Dpt of Sociology, Uppsala University.

Raghavan, R. 2009. Ethnicity and Intellectual Disability. In: Bollard, M. (ed.). Intellectual Disability and Social Inclusion. A critical review. China: Livingstone Elsevier.

Sankhla, D. and Theodore, K. 2015. Attitudes towards Sexuality in Men and Women with Intellectual Disabilities: A Comparison between White Westerners and South Asians, Sexuality and Disability 33: 429-445.

Schlytter, A. and Linell, H. 2010: Girls with honour-related problems in a comparative perspective. International Journal of Social Welfare 19(2): 152-161.

TRIS. 2012. Trippelt utsatt: Hedersrelaterat förtryck och våld bland ungdomar med intellektuell funktionsnedsättning [Tripled Oppressed. Honor-related oppression and violence among youth with intellectual disabilities]. Stockholm: Projekt Nå.

UN Women. 2017. Facts and figures: Ending violence against women. http://www.unwomen.org/en/what-we-do/ending-violence-against-women/facts-and-figures (2016). Accessed 6 February.

WHO. 2017. Female genital mutilation. http://www.who.int/mediacentre/factsheets/fs241/en/ (2017). Accessed 6 February 2017.

Socialstyrelsen. 2016. Vänd dem inte ryggen - utbildningsmaterial om hedersrelaterat våld och förtryck [Don't turn them back - education material on honor related violence and oppression]. http://www.socialstyrelsen.se/Lists/Artikelkatalog/Attachments/19317/2014-16.pdf (2014). Accessed 20 December 2016.

Socialstyrelsen [National Board of Health and Welfare] and Folkhälsomyndigheten [Public Health Authority]. 2014. Underlag för nationell strategi för sexuell och reproduktiv hälsa och rättigheter [National strategy for Sexual and Reproductive Health and Rights]. Stockholm: Socialstyrelsen [National Board of Health and Welfare].

Svensson P.G. and Starrin B. (eds.) 1996. Kvalitativa studier i teori och praktik. Lund: Studentlitteratur.

Tilley, E., Walsley, J., Earle, S. and Atkinson, D. 2012. "The silence is roaring"; 
Sterilization, reproductive rights and women with intellectual disabilities. Disability and Society 37: 413-426.

Wibeck, V. 2010. Fokusgrupper: om fokuserade gruppintervjuer som undersökningsmetod [Focus Groups. On Focus Groups Interviews as a Research Method]. Lund: Studentlitteratur. WHO. 2010a. WHO regional strategy on sexual and reproductive health. Denmark: WHO Regional office for $\quad$ Europe. http://www.euro.who.int/_data/assets/pdf_file/0004/69529/e74558.pdf (2001). Accessed 20 December 2016.

WHO. 2010b. Developing sexual health programmes. A framework for action. http://apps.who.int/iris/bitstream/10665/70501/1/WHO_RHR_HRP_10.22_eng.pdf (2010). Accessed 20 December 2016.

Vetenskapsrådet [The Swedish Research Counsil] and Uppsala University. 2018. CODEX rules and guidelines for research. http://codex.vr.se/en/index.shtml (2016). Accessed 10 February 2017.

Östman, M. 2008. Migration och psykisk ohälsa [Migration and Psychological Unhealth]. Malmö University, FoU Rapport 2008:3. 